OPEN ACCESS

Edited by:

Rukhsana Ahmed,

University at Albany, United States

Reviewed by:

Rasha El-Ibiary,

Future University in Egypt, Egypt James Olumide Olufowote, University of Oklahoma, United States

${ }^{*}$ Correspondence: Hagos Nigussie hagos.nigussie@mu.edu.et

Specialty section: This article was submitted to Health Communication, a section of the journal Frontiers in Communication

Received: 15 May 2020 Accepted: 04 May 2021

Published: 21 May 2021

Citation:

Nigussie H (2021) The Coronavirus Intervention in Ethiopia and the Challenges for Implementation.

Front. Commun. 6:562512. doi: $10.3389 /$ fcomm. 2021.562512

\section{The Coronavirus Intervention in Ethiopia and the Challenges for Implementation}

\author{
Hagos Nigussie * \\ Department of Journalism and Communication, Mekelle University, Mekelle, Ethiopia
}

The coronavirus has been rapidly spreading across different parts of the globe. The pandemic will have a severe impact unless coordinated preventive measures are undertaken. This paper examines the COVID-19 intervention and the challenges for implementation in Mekelle, Tigray, northern Ethiopia. Telephone interviews, personal observation and document reviews were used as data collection techniques. Results showed that the majority of the population in Mekelle are aware of the pandemic. Most people practiced handwashing with soap and water. But there is limited physical distancing in religious institutions, market places, and coffee houses where many people convene. With this, staying at home remains a challenge among the majority. Still, there is a belief that the pandemic is a "punishment from God", while others believe that it is an illness of the old and does not affect the young. Generally, applying the recommended COVID-19 prevention measures, including the physical distancing, seem unattainable as the majority continue to overlook government advice. As related studies such as the fight against the Ebola outbreak in West African countries showed, this emanates from the lack of trust in media messages. In Tigray, religious leaders and community elders have a significant influence on their respective community members. Messages from these individuals remain trusted and can easily reach the majority due to social networks. This highlights that besides enforcing strict and prolonged measures from the government, reliable two-way communication can help achieve the desired behavior changes towards complying with the COVID-19 prevention measures among the different segments of the population in Mekelle.

Keywords: COVID-19, physical distancing, communication, behavior change, mekelle, Ethiopia

\section{INTRODUCTION}

The COVID-19 pandemic continues as a significant worldwide health threat. The World Health Organization has declared it a public health emergency of global concern calling for concerted efforts from across all nations to stop the spread of the virus (World Health Organization, 2020). Most African countries face an enormous mission to contain the rapidly spreading pandemic due to poor healthcare and limited resources. However, the Mo Ibrahim Foundation (2020) debates that the continent appears to have comparative advantages to contain the pandemic. The foundation's claims are based on two viewpoints. First, it is related to the demography as most of its population is in the age of lower than 20 years. The assumption is that younger populations appear to suffer milder symptoms compared to older people. Second, it is associated with a warm climate in that influenza 
and respiratory viruses mainly transmit during cold rainy seasons. This is related to earlier studies that "high temperature and high relative humidity significantly reduce the transmission of COVID-19" (Wang et al., 2020, p.1). Nevertheless, this was immediately overruled, affirming that the virus could be transmitted to all areas, hot and humid climates (World Heath Organization, 2020b). Based on this, there is no concrete evidence to recognize the foundation's claims as the COVID-19 is a new pandemic with no explicitly recommended antiviral treatment or vaccine to date. However, these claims represent the rapidly circulating myths and misconceptions in most African countries, including Ethiopia.

Although most low-income countries are in the early stages of the pandemic, there are considerable uncertainties regarding the trajectory of the disease. Higher transmissibility is expected in such settings due to larger household sizes, overcrowding and inadequate water and sanitation, which will affect the adoption of recommended preventive measures (Dahab et al., 2020). Ethiopia is exceptionally vulnerable to the pandemic due to its relatively tenuous health systems, inadequate infrastructure, population mobility, and susceptibility to social and political unrest. Thus, it becomes a priority for the nation to implement effective intervention strategies to contain the rapidly transmitting virus. After the first COVID-19 case on 13 March 2020, the Ethiopian government has adopted different measures endorsed by the World Health Organization. These measures include informing the public about regular handwashing with water and soap, physical distancing, contact tracing, self-isolation and quarantine measures. Also, the government has announced school and workplace closures, limited public gatherings and establishing COVID-19 task forces at different levels. Similar measures proved effective in reducing the spread of the virus in different countries, including New Zealand, China, Singapore and South Korea.

On 26 March 2020, in addition to the measures mentioned above, the Tigray state government has declared a region-wide state of emergency to prevent the spread of the virus. Within the region, all travels have been banned for 15 days (extended until June 2020). A ban was put on all social activities, mass gatherings such as in market places, religious institutions, cafes and restaurants (with some amendments at later stages); to ensure physical distancing. Despite these measures, the number of COVID-19 cases is increasing in Ethiopia, with 54,409 cases reported as of 2 September 2020 (Ethiopian Public Health Institute, 2020). As of 5 October 2020, a total of 6070 confirmed COVID-19 cases and 37 deaths in Tigray. The most significant proportion, 2,270 (37.4\%), of the cases were in the age group of 25-34 years, followed by 1,872 (30.84\%) in the age group 15-24 years (Tigray Regional Health Bureau Report, 2020).

The numbers mentioned above do not distinctly show the exact level of the pandemic in the country and Mekelle. This is because the number of COVID-19 cases depends on the testing capacity of nations. For instance, from March 13 to mid-April 2020, Ethiopia did not have its COVID-19 testing laboratory and sent samples to South Africa. Later, there was only one testing center in the capital Addis Ababa, and samples from different parts of the country were sent to the capital. Although there are testing centers in most cities, including Mekelle, they are inadequate compared to a large number of populations in the country. Therefore, low testing capacity affects population-based testing rates and data about the overall status of the pandemic in the country. With the rapidly transmitting virus, it is clear that the number of cases could significantly increase in Mekelle. However, due to the genocide in Tigray by the Ethiopian PM Abiy Ahmed ${ }^{1}$, there is a blackout since the end of October 2020. Most of the public health service centers and media houses have been partially working or destroyed. Hence, it is challenging to obtain the exact figure about the status of COVID-19 cases in Mekelle.

\section{Social Media and the COVID-19 Pandemic}

Social media became significant sources of information for the public, often covering different themes. Studies have shown that social media have become the primary sources of health information and public engagement (Moorhead et al., 2013; Fernández-Luque and Bau, 2015; Freeman et al., 2015). They are highly cost-effective for information exchange among individuals supporting public health education (Obar et al., 2012; Scott and Maryman, 2016). Social media contributed to fundraizing within China and outside its borders during pandemics, enabling scientists to collaborate, brainstorm and identify solutions (Sokolov, 2020), become useful in tracking diseases (Yasinski, 2020). Social media were also effective in disease mapping (Signorini et al., 2011). However, different factors are affecting the use of social media for health communication. One of them is a growing level of misinformation and fake news through these platforms. Misinformation refers to false information disclosed without the intention of harming others (Jack, 2017). But certain practices are taken as dangerous because of their disruptive effect rather than their deceiving content (Bayer et al., 2019). The spread of false information can have severe consequences for public health (Scheufele and Krause, 2019). Misinformation is associated with severe public health consequences, such as increased public fear and loss of vaccine confidence (Larson et al., 2014; Larson, 2018). Different studies have documented that social media are used to spread harmful health messages, including anti-vaccine rhetoric (Dunn et al., 2015; Tomeny et al., 2017), misinformation about the Zika virus (Sharma et al., 2017) and Lyme disease (Basch et al., 2017); and the Ebola-related prevention and treatment strategies (Oyeyemi et al., 2014).

With the spread of COVID-19, Tedros Adhanom, the Director-General of the World Health Organization, claimed that "We're not just fighting an epidemic; we are fighting an infodemic" (World Heath Organization, 2020c). This shows that misinformation is common, and it is equally affecting the COVID-19 prevention campaigns. Misinformation about the COVID-19 is rapidly spreading (Chakravorti, 2020; Taylor, 2020). The BBC's Reality Check (2020) has listed down several

${ }^{1}$ Abiy Ahmed is the 2019 Noble Prize winner for Peace. Yet, in November 2020, he declared genocide in Tigray. He used rape and hunger as weapons of war. Jointly, the Ethiopian military forces, the Amhara Militia, and the Eritrean military forces have committed unspeakable civilian atrocities in Tigray. 
COVID-19-related misleading information that has widely spread throughout the African continent. These include consuming alcohol as throat sanitizer (a governor of Nairobi, Kenya); urging Africans not to wear blue face masks claiming they are contaminated with toxins (Amazon); wearing a mask warrants protection from the virus and that if wearing them, social distancing is needless (a regional governor, Nigeria); and inhaling hot steam can kill the virus (Tanzanian president) among others.

Another misinformation comes from the government of Madagascar who declared that the country had produced herbal tea as a remedy for the COVID-19. The nation's president Rajoelina claims the validity of the herbal tea asserting that "Tests have been carried out and two people have now been cured by this treatment" (Times of Israel, 2020). Despite these claims, the World Health Organization warned that, to date, there is no specific medicine recommended to prevent or treat the coronavirus. The African Center for disease Control (CDC) has requested further details from Madagascar about the reliability of the proposed herbal medicine. Along with the widely disseminated misinformation, myths and cultural barriers are significantly affecting the pandemic intervention in Africa. Padayachee and du Toit (2020) compiled several myths that have been extensively disseminated in African countries. Some of the myths include that the COVID-19 does not affect Africans; the coronavirus cannot survive in Africa's warm climate; spray alcohol and chlorine all over your body to protect the coronavirus. WHO declared that besides the pandemic threat, an infodemic had been generated by a large amount of information available on the matter (World Heath Organization, 2020a). However, most nations, including Ethiopia, have limited techniques to block the spread of misinformation.

\section{Public Health Emergency and Social Behavior}

The social behavior in a given setting determines the level of transmission of a pandemic (Del Valle et al., 2005; Xiang et al., 2016). Accordingly, employing behavioral and social interventions have become indispensable to alleviate the impacts of outbreaks. Interventions should be based on "community engagement, participation and ownership and on intersectoral coordination and collaboration for prevention, control and mitigation strategies to work" (World Health Organization, 2012, p.vi). During public health emergency, mass media play significant roles in disseminating messages to educate the public about the pandemic and its preventive measures. However, most of them do not recognize the context of intervention. Understanding the context becomes indispensable as the nature and scope of public health education may differ based on the intervention setting and the level of risk perception among the public. This is whether to focus on individual behavior or collective behaviors of the target population. It is related to Hofstede (2001) concepts of collectivism and individualism, which suggest that while individual-based decisions are appreciated in developed western countries, collective decisions are valued in some developing countries.

In western countries, individual behavior would be decisive to control the spread of COVID-19 rather than government action (Anderson et al., 2020). However, in Ethiopia, where family attitudes hold a significant part of the community than individual roles (Ethiopian Public Health Institute, 2005), and individually referenced health interventions may not sufficiently achieve the desired behavior changes. But most of the behavior change intervention strategies, as Singhal (2003, p. 21) asserts, "focus on the tree and not enough on the forest of which the tree is a part." Related studies about HIV/AIDS in Africa have shown that intervention programs focusing on individuals have failed as they lacked community orientation (Panos, 2003; Singhal, 2003; Singhal and Rogers, 2003; Airhihenbuwa and Obregon, 2006). One of the challenges of interventions of these type is that they lack a precise analysis of the target behavior as they mostly focus on implicit common-sense models of behavior (Michie et al., 2009).

\section{Public Health Intervention in Ethiopia}

The Ethiopian public health intervention focuses on preventionorientated public health policy. The Ministry of Health $(\mathrm{MOH})$ implements the intervention through the Health Extension Program using Health Extension Workers (HEWs). This program is a platform for delivering primary health care (Assefa et al., 2019) through regular public health education. This pivotal role in achieving the Millennium Development Goals in Ethiopia. The country has got global recognition and remarkable success in achieving most of the health MDGs, including " $67 \%$ reduction in under-five mortality, a $71 \%$ decline in maternal mortality ratio, a $90 \%$ decline in new HIV infections, a decrease in malaria-related deaths by $73 \%$ and a more than $50 \%$ decline in mortality due to tuberculosis" (Assefa et al., 2017, p.5). A recent study about the Health Extension Program in Ethiopia has concluded the central role of health extension workers in ensuring a well-functioning primary health care system (MERQ, 2019).

Despite encouraging trends in public health intervention in the country, there are limitations. One of the limitations is that most public health intervention programs are top-down in format limiting community engagement. Communities have defined roles in problem identification and strategy implementation to promote holistic response to achieve the desired health intervention. There are no clearly recognized health communication strategies for rural and urban settings. This shows that a limited understanding, practice and research about the role of communication in public health. World Heath Organization (2011) argues that the instrumentality of effective health communication strategies appears to have been ignored in most parts of Sub-Saharan African countries, and apparently, Ethiopia joins this category.

Several studies examined health communication in Ethiopia. Most of them focused on family planning and HIV/AIDS prevention campaigns (see Cho and Witte, 2005; EPHI, 2005; Farr et al., 2005; Getachew, 2005; Gulilat, 2006; Tibebe, 2006; Hiwot, 2007; Zelalem, 2010; Bekalu and Eggermont, 2013; 
Nigussie, 2019). These studies indicated that health communication positively contributed to raising awareness of target populations about respective health issues. However, their roles in promoting behavior changes were minimal. Different factors affected behavior changes of populations towards risky behaviors. First, most of the campaigns have focused on urban areas with extensive use of media. Media has played a significant part in informing the public about the epidemic (Farr et al., 2005; Zelalem, 2010). However, programs that broadcast from urban centers may fail to improve the HIV/AIDS knowledge of rural people and disadvantage them relative to their urban counterparts (Bekalu and Eggermont, 2013). Consequently, the country has shown some of the greatest differences in AIDS awareness across its regions. For instance, striking lack of knowledge in the Somalia, Gambela, and Benishangul-Gumuz regions; the Somalia region had the lowest levels of awareness as only $50 \%$ of women, and $64 \%$ of men had heard of AIDS-and this lack of knowledge was evident across all HIV/AIDS knowledge domains (CSA, 2016). Second, the behavior change communication strategies primarily focused on individuals (Ethiopian Public Health Issue, 2005; Nigussie, 2019). Nevertheless, a health system that is individually referenced to lifestyle risk factors and underpinned by a biomedical model will be doomed to failure as it applies a "one size fits all" policy ignoring cultural differences (Farmer et al., 2012). One size fits all rural health package limitations because it affects the diversity and choice of experiences that can be offered for all cultural groups (Sypek et al., 2008; McBain-Rigg and Veitch, 2011). This shows that the health communication field has been "missing the message" because it has concentrated on "putting out messages [rather than] fostering an environment where the voices of those most affected ... can be heard" (Panos, 2003, p.22). Third, the epidemic intervention communication strategies are not contextspecific, as there are no clearly stated communication strategies for rural HIV/AIDS prevention campaigns (Getachew, 2005; Nigussie, 2019).

In Ethiopia, where people are conservative to culture and religion, it requires employing coordinated and inclusive public health education rather than uniquely relying on media messages. Religious organizations and community elders can play vital roles in raising the awareness of their respective community members about the pandemic. Therefore, it is essential to design health communication strategies that fit the specific setting to promote community engagement and collective action. Particularly during outbreaks, communicating health messages requires special attention. During an emergency, all affected people take information differently, process it in their way and act differently (Reynolds et al., 2002). One of the essential measures for pandemic prevention is implementing national risk communication and community engagement plans using existing pandemic influenza or other public health communication procedures (World Health Organization, 2020d). Risk communication helps people develop a sense of control over their health and safety, which allows them to react to risk factors with more reasoned responses (World Health Organization, 2005). Also, it is helpful to build trust in the response and increases the probability that health advice is followed. It minimizes and manages false rumors and misinformation that undermine the response and may lead to further disease spread (World Heath Organization, 2018). However, Ethiopia does not have a full-fledged Risk Communication and Community Engagement (RCCE) readiness nor the experience in handling pandemics the world has faced previously, such as SARS or Ebola. In Ethiopia, culture, religion and social ties determine the way people respond to public health interventions. Thus, achieving the COVID-19 interventions in Mekelle relies on understanding the broader context of the intervention setting rather than simply focusing on disseminating the pandemic-related messages. This study examines the levels of applying the recommended COVID-19 prevention measures in Mekelle and the challenges for implementation. It focuses on the following questions:

1. What is the level of awareness of people about the COVID19 in Mekelle?

2. What is the level of applying the recommended COVID19 prevention measures in Mekelle?

3. What are the factors (if any) affecting the implementation of the COVID-19 prevention measures?

\section{The Study Context}

Ethiopia is located in the horn of Africa and is known as one of the oldest nations on the continent. It occupies 1.1 million square kilometers and is bordered by Eritrea to the North, Djibouti and Somalia to the East, Sudan to the West and Kenya to the South. Based on Worldometers (2021), Ethiopia has a population of $116,690,885$. Nevertheless, it is challenging to get the exact official figure as the country did not undertake Population and Housing Census after May 2007. With the current population, the country becomes one of the most populated nations in east Africa and the second most populated nation in the continent, next to Nigeria. Ethiopia is a diverse country with more than 80 ethnicities, varied geographic and climatic conditions, rich traditions and multifaceted history.

The major languages in Ethiopia are Oromifa, Amharic and Tigrigna. However, due to the federalism system, each region has its respective office language. Tigray is one of the states within the Federal Democratic Republic of Ethiopia, with total area coverage of $80,000 \mathrm{~km} 2$. It is located in the northern part of the country and its capital Mekelle is $762 \mathrm{~km}$ away from the country's capital, Addis Ababa. Tigray borders with Eritrea from the north, Sudan in the west, Afar Regional State in the east and Amhara Regional State in the southwest. Mekelle is $783 \mathrm{~km}$ away from Addis Ababa, the Ethiopian capital, with a population of 524,000 people (Population Stat., 2020). High levels of poverty characterize most parts of Ethiopia. Still, most people rely on food aid for their survival. More than 8 million people are currently estimated to require food assistance in Ethiopia, 4.5 million acutely malnourished residents, and 9.5 million need non-food emergency assistance (Mercy Corps, 2020). In Tigray, there is a high level of poverty. The poverty levels in Tigray were found $61.4,48.5$ and $31.8 \%$ in 1999/00, 2004/05 and 2010/11, respectively, while the 2015/16 survey result shows that the poverty rate of Tigray has declined to 
27\% (Central Statistics Agnecy, 2016). However, this makes the region's situation more dangerous compared to the national average of 23.4\% (World Bank 2017; cited in Dejene and Cochrane, 2019). The COVID-19 has posed additional challenges to alleviate poverty. Based on the Economic Commission for Africa (2020) report, it is estimated that between 5 million and 29 million people will be pushed below the extreme poverty line of $\$ 1.90$ per day due to the impact of COVID-19. This will have a tremendous impact on low-income earners, including daily laborers in the construction sector, informal businesses, and street vendors.

\section{MATERIALS AND METHODS}

This study employed a case study. The case study has been espoused in social science and health care research for many years (Stake, 2008; Creswell, 2012; Yin, 2012). Swanborn (2010) indicated that cases could be located at the micro (persons and interpersonal relations), meso (organization, institution), or macro levels (communities, democracies, societies) and involve one actor or multiple actors. The case study becomes relevant as it is useful for discovering new behaviors, processes, or anything we have little knowledge of it, responding to how and why questions about a contemporary set of events (Meyer, 2001, p. 330).

This study was undertaken in Mekelle, the Tigray capital, in northern Ethiopia. There are different reasons to select Mekelle. First, as the capital, it is one of the most densely populated cities in Tigray. The pandemic seems mostly critical in dense urban settings, often with a fast transmission (Florida, 2020). Second, Mekelle is a gateway for people travelling to and from Addis Ababa, where the majority of the COVID-19 cases are reported. Third, there is a high level of population mobility from rural to urban, including to Mekelle and vice versa. This study was undertaken purely on qualitative research principles, and telephone interviews, personal observation and document reviews were used as data collection techniques. The study subjects were journalists (private and government), health experts (private clinics and government hospitals) working in the frontlines, religious leaders, and the general public.

Telephone interviews: Due to travel restrictions in Mekelle, it was challenging to undertake face-to-face interviews. I could not use video-calling (Skype/Zoom) due to a limited internet connection in the city. Thus, a telephone interview was used to contact interviewees. Telephone interviews have several advantages. It is cost-effective, allowing interpersonal communication without a face-face interaction (Carr and Worth, 2001). Telephone interviews provide higher levels of anonymity and privacy (Carr and Worth, 2001; Holt, 2010; Vogl, 2013); as many people are shy and are not comfortable with face-to-face interactions (Tucker and Parker, 2014). This study used a semi-structured interview format; and adopted a conversation style approach (Kvale and Brinkmann, 2008; Rowley, 2012). Interviewees were purposefully selected based on their roles in the COVID-19 intervention campaigns. Interviewees comprised journalists (both private and government), health experts, and religious leaders.
Thirty-five individual interviews were held, each lasting 15-20 minutes. Interviewees comprised 6 religious leaders (Catholic (1), Orthodox (2), Muslim (1), and protestant 2) participants; 6 health experts (3 from private clinics and 3 from government hospitals); and 23 journalists (4 from FM 104.4; 4 from Dimtsi Weyane radio; 8 from DW TV; and 7 from Tig TV).Telephone interviewing has limitations. One of the limitations was creating a good interview ambience, including ensuring participants are comfortable and interview distractions are kept to a minimum. Also, there were instances of mobile network failures and mobile phones getting switched off during interviews. With this, some interviewees were reluctant to answer calls despite prior consent for the interview.

Personal observation: A total of 15 hours of personal observation was undertaken in selected sites in three rounds.The personal observation was used to observe, recognize and record the levels of practicing the recommended COVID-19 prevention measures by the general public in Mekelle city. In relation to what to observe and how to observe, Gobo (2008, p.162) outlines three issues, including the "social structures, common-sense interpretations/explanations given by individual participants and the context of action." This can be attained using a focused observation by recording actions using a checklist of questions to "tick off pre-established actions" (Marshall and Rossman, 2014, p.139).

For personal observation, sites were purposefully selected, including market places, churches/mosques, and coffee houses where a large number of people congregate. Observation focused on to what levels people practice handwashing with water and soap; the extent of applying physical distancing; whether the public used face masks; avoided visiting crowds, and the homestay subsequent government measures. Personal observations were undertaken in three rounds (at early stages of the pandemic, soon after the lockdown and stay-at-home measures, and after the government lifted the lockdown measures) to evaluate the continuity or disparities in complying with the recommended prevention measures.

Document reviews: Document reviews for this study focused on four editorial policy documents from private and government broadcast media houses (radio and TV) in Mekelle. The media houses were the Tigray television station, the Dimtsi Weyane radio, FM Mekelle 104.4 and the Dimtsi Weyane television stations. These media houses were purposefully selected based on their relevance for health education-related programs and to examine the extent of coverage of the COVID-19-related news and programs in each of them.

\section{DATA ANALYSIS AND DISCUSSION OF RESULTS}

\section{Data Analysis}

Data analysis was undertaken qualitatively using thematic analysis. Audio outputs in the local language (Tigrigna) were transcribed into English, and responses were coded in a matrix that contains different thematic categories. Then, tabulated responses were thematically ranked from the most frequently 
mentioned to the least frequent ones. Observation-based field notes were coded into themes based on the matrix of observation to identify and formulate all ideas, themes or issues they suggest (Emerson et al., 2011). Document analysis was made based on the procedures described by Startt and Sloan (2003). The procedures focused on the evidence, the context, and constructing generalizations (ibid, pp. 201-202). Finally, observation-based field notes and tabulated responses from the interview and extracts and texts were carefully analyzed so that sensible meanings emerge from the recurring themes.

\section{Ethics Statements}

For this study, ethical clearance was reviewed and obtained from the Ethical Review Committee at the College of Health Sciences, Mekelle University. The participants provided their written, informed consent to participate in the study. Choices of participants are adhered to in the research process, including the choice to withdraw from the study at any stage. The identity of the research participants was kept confidential. All the quotations from the interviewees have been attributed to pseudonyms.

\section{DISCUSSION}

\section{Media Coverage of the COVID-19 in Mekelle}

As a new public health emergency, the COVID-19 has received extensive media coverage globally. It has been much more prominent in the media than the recent pandemics, including Ebola (Wahl-Jorgensen, 2020). In Mekelle, both private and government media houses have produced several news and programs about the pandemic. Editorial policy documents from the Tigray television, the Dimtsi Weyane television, FM Mekelle 104.4, and the Dimtsi Weyane radio stations showed that each media house has extensively covered the pandemic-related news and programs. The COVID-19-related programs in these media houses focused on different topics, including COVID-19 and gender, psychology, food security, agriculture, and investment. But there are differences in the levels of news and program coverages within these media houses. The Tigray television had the most coverage (138 news and 45 programs); the Dimtsi Weyane television (45 news and 36 programs); FM Mekelle 104.4 (52 news and 39 programs); and the Dimtsi Weyane radio (43 news and 38 programs). Despite these differences in the news and programs, these media houses have broadly covered the pandemic to educate the public. Nevertheless, extensive media coverage of the pandemic may not necessarily pledge to realize the contents of the message. Instead, it is a one-directional information dissemination mechanism and does not mean individuals are effectively communicated to; they are simply exposed to "information dumping" (Moemeka, 2000, p. 9). The basic reason for this is that people have different levels of understanding and interpreting media messages, which determines their response towards the COVID-19 messages. This highlights the need to broadcast consistent messages to different audiences as each may have varying levels of perception and response to a crisis.
Responses of audiences to a crisis can be categorized into three groups: freeze, flight and fight (Bracha, 2004, p.679); each pattern involving different communication forms. The freeze cluster entails clear incentives to make people more alert to the risks they are facing, and the flight cluster needs to be informed that even within isolation, there are risks that will need to be addressed (Collins et al., 2020, p.5). But the fight cluster involves good advice on how to channel their need for action into behavioral responses that reduce the risk to themselves and others while avoiding blaming others who are alleged to be causing or amplifying the risk (Renn, 2015). Yet, there are no programs specific to different segments of the population, including the marginalized and vulnerable groups, who constitute a significant number in Mekelle. In relation to this, a radio journalist argues that:

We know that there are listeners with diverse needs and priorities. Unfortunately, our media does not have programs explicitly focusing on these individuals. But designing programs specific to their needs become helpful in promoting inclusive and coherent media messages.

Besides the lack of classifying audiences, there are limited local sources to design context-based pandemic-related news and programs. Affirming this, a TV journalist contends that:

...there are limited sources locally that can provide detailed information about the COVID-19. Mostly, we rely on international media to produce news and programs. However, it is challenging to translate and contextualize the information we obtain from foreign sources.

These views highlight that media houses produce the COVID19 news and programs without realizing these factors and the context of intervention, which may restrain the awareness levels of different segments of the public in Mekelle.

\section{The Level of People's Awareness About the COVID-19}

Communicating relevant, accurate, and timely health information to at-risk populations is a critical factor for promoting public health (Kreps and Maibach, 2008). Media plays a significant role in informing the public about pandemics (Farr et al., 2005; Rubin et al., 2010). An essential component of media is messaging relevant information, which educates the public with what is known about the virus and information about health behaviors that can reduce individuallevel risk (Frieden and Lee, 2020). Results showed that extensive media coverage about the COVID-19 has helped to raise the awareness of people in Mekelle. A TV journalist describes this as:

At the early stages of the pandemic, there were confusions. But currently, there are great levels of awareness among the people in Mekelle. Each time 
we ask respondents in different parts of the city, we get a good level of awareness about the COVID-19 and its prevention methods.

A health expert from a public hospital also adds that:

With the rising levels of misinformation, getting the right information about the COVID-19 is challenging. But most people seem that they are well informed about it. Each time you ask them about it, they give you details. This shows increasing levels of public awareness about it.

The above assertions are consistent with other studies about the roles of media in creating awareness about public health, leading to positive behaviors and prevention practices (Wakefield et al., 2010; Wakefield et al., 2011; Jung et al., 2013; Collinson et al., 2015; Majumder et al., 2015). Notwithstanding the levels of media coverage, several factors determine positive behavior changes and collective action toward pandemic prevention. Notably, designing context-based COVID-19 news and programs becomes vital to educate the majority of the public. In Mekelle and other parts of Tigray, people are highly interconnected through religion, kinship and cultural ties. Understanding these factors helps to design messages consistent with the values and cultural positions of people. Also, it promotes community engagement in the production and dissemination of the COVID-19 messages. However, a lack of understanding of the context would neither "take the people into confidence; nor attempt to learn from them" (Moemeka, 2000, p. 4). Community engagement promotes trust in the media messages as community members become key actors in information generation and raise their awareness levels leading to behavior change.

\section{The Level of Applying the Recommended COVID-19 Prevention Measures}

With no explicitly recommended antiviral treatment or vaccine for the COVID-19 to date, it requires realizing the recommended prevention measures. Containing the rapidly spreading virus relies on the public having accurate perceptions of personal and societal risk factors. This becomes vital as people's behavior can fundamentally influence and alter the spread of a pandemic (Funk et al., 2009; van Bavel et al., 2020). Observation results showed that most people in Mekelle had demonstrated the readiness to apply the recommended COVID-19 prevention measures during the early stages of the pandemic. Most of them practiced regular handwashing with soap and water, wore face masks, utilized sanitizers, and stayed at home due to closures to schools and government offices. However, there were limited practices in physical distancing, notably in churches and mosques, market places, coffee houses and restaurants where a large number of people congregate. Based on this, it can be argued that the majority of the public has continued to neglect government advice about physical distancing.
One of the reasons for this is that, still, there is a belief that the pandemic is an illness of the old and does not affect the young. Therefore, despite diverse COVID-19 education programs through different media, most people, particularly the young generation, ignore these messages. The reason to overlook them can be the lack of preparedness from the public to cooperate and implement the recommended prevention measures. In Mekelle, it seems business as usual for most people despite the mounting numbers of the COVID-19 cases. Hence, it requires identifying the factors preventing these individuals from applying the COVID-19 prevention measures.

\section{Factors Affecting the Implementation of the COVID-19 Prevention Measures}

Most nations have shown the readiness to realize the COVID-19 prevention measures. But others, notably the developing countries, are struggling to deal with it. There are different reasons for the differences in implementing the recommended pandemic prevention measures. One of the reasons is related to the degree of preparedness and resource mobilization of nations. Ethiopia has a flawed healthcare system and limited resources to control the pandemic. Hence, educating the public becomes a priority to contain the rapidly spreading virus. Journalists and health experts were given the responsibility to educate the public. However, it was challenging for both professionals to handle their duties effectively. Results showed that journalists experienced different challenges in covering the pandemic. A TV journalist describes it as:

Covering the COVID-19 is a challenging job for journalists in our context. Some of the challenges posed to journalists include the lack of adequate knowledge about the pandemic, lack of personal protective equipment and the widely disseminating misinformation among the public.

Similarly, a radio journalist also adds that:

Producing news and programs about the COVID-19 is demanding. As the pandemic is new, you do not get as many details as required. The sources you contact may not provide you with detailed information. With this, each time you reach sources, there is a high degree of uncertainty about personal and family safety issues.

Health experts working in the frontlines also face several challenges that affected their pandemic prevention campaigns. About this, a health expert from a government hospital contends that:

We have been working a lot to educate our people about the COVID-19 and its prevention measures. However, the pandemic has caused fear and confusion among the public, which affected our intervention efforts. Similarly, as professionals, we face insecurity in our lives. 
The issue of fear and confusion about the pandemic from the professionals and the public can affect the pandemic intervention efforts. Also, shortages of personal protective equipment have significantly affected the interest of professionals to engage in the COVID-19 prevention campaigns. Thus, the challenges mentioned above require special attention both from the media houses and respective government offices. Other challenges affecting the COVID-19 prevention in Mekelle are the widely spreading myths and misconceptions, religious proclivity, and the poverty and livelihood concerns of the public.

\section{Myths and Misconceptions About the COVID-19}

Myths and misconceptions have tremendously affected the COVID-19 prevention efforts in most African countries (Frenkel et al., 2020; Russonello, 2020). Since the first COVID-19 case in Ethiopia, several myths and misconceptions have circulated among the public. One of the commonly mentioned myths in Mekelle was eating spicy food to protect the virus. Others advocated that washing your body with "Holy water" protects from the virus. Consequently, several people traveled to "Holy water" centers even though the government introduced restrictions against it at later stages. The other most widely disseminated myth among the general public was consuming lemon juice, garlic and ginger to prevent the virus. Observation results showed unanticipated inflation in prices of these items in the markets. Social media has exacerbated the dissemination of these myths that further intensified the confusion among the public. Moreover, several COVID-19related misconceptions were circulating among the public in Mekelle. One of the commonly mentioned misconceptions was that the pandemic is an imported disease manufactured in the US laboratory to reduce the rapidly growing populations in Africa. The persistence of myths and misconceptions forced people to rely on traditional medicine and cultural practices to prevent the pandemic. This can be related to the lack of trust in the government's preparedness and ability to respond to the pandemic. This is consistent with other studies in Sierra Leone about the government's incompetence to prevent the Ebola pandemic (Prati and Pietrantoni, 2016; Yamanis et al., 2016).

Ethiopia is in an uncertain political environment where there is mistrust between the federal government and regional governments. Likewise, there is confusion among the public that the COVID-19 prevention campaigns might have been compromised for political gains. For instance, one of the confusions that led to the mistrust toward the government was Ethiopian Prime Minister Abiy Ahmed, who publicly declared that the nation is extracting a herbal medicine that cures the virus. Although this claim is against the guidelines and procedures outlined by WHO, the PM insisted that the nation is extracting the herbal. This is unrealistic and shows interest in political gains rather than a coordinated effort to fight against the pandemic. These messages, along with the rapidly disseminating misinformation, have significantly affected the pandemic prevention efforts. However, there are no systems in place to regulate the COVID-19-related misinformation in Ethiopia, nor are there timely media responses about the misleading information.

Globally, there is limited research about disseminating false information during health emergencies (Pulido et al., 2020). Therefore, it requires debunking the myths and ending the traditional medicine hype. Experience from the HIV/AIDS pandemic shows similar perceptions and limited behavior changes, which claimed many lives in Mekelle and other parts of the country. Hence, it should be an excellent lesson in realizing the COVID-19 prevention campaigns through holistic response. This can be attained through providing accurate and appropriate information from the media, health experts and relevant government offices. Equally, it is essential to realize the peculiarities of the intervention setting and utilize risk communication and community engagement strategies accordingly.

\section{Religious Proclivity Among the General Public}

Culture and religion are an integral part of the social and moral fabric of the people in Mekelle. Accordingly, most people favor participating in cultural and religious activities. Despite the measures to avoid crowds and public gatherings, most people continued to participate in the cultural and religious ceremonies in Mekelle. Observation results showed that a large crowd attends funeral rite, and the majority of the Christian religious followers attend the "Sunday Mass" and other religious events. The same applies to Muslims attending the "Friday Prayers" and funeral rites. Therefore, irrespective of the awareness levels about the pandemic, many people are failing to comply with the recommended COVID-19 prevention measures. Some of the factors leading to negligence to prevention measures include cultural and religious misunderstandings and misinformation about the virus. Results showed that the majority of the public in Mekelle still believe that the COVID-19 is a "punishment from God" or "Allah" due to people's immoral acts. In relation to this, a religious leader argues that

The coronavirus is one of the most worrying pandemics we have experienced. I believe that it is a result of our sinful acts. ... we need to cleanse ourselves and become closer to Him. We need to unite and pray for His forgiveness.

Another religious leader also adds that:

...I believe that voracity and individualism are dominating our world. This is not what we have learned from Him. Thus, we need to pray and come back to the basics of our religious teachings. That is the only way to fight the virus.

Others accentuated the power of praying to prevent the severe impacts of the pandemic. Emphasizing this, a religious leader argues that: 
Most nations, including those with quality healthcare, are struggling to cope with the dreadful impact of the pandemic. We do not have the resources to prevent it. We pray for His absolution. Had it not been for the power of God, the impact of the pandemic would have been worse than anyone can imagine.

Acknowledging the power of praying to prevent the anticipated impact of COVID-19, the Ethiopian InterReligious Council has declared a nation-wide one month of prayers earlier in March 2020. Religious leaders believed that this program incites family solidarity, inspiring people to practice the recommended measures through family influence. Religious leaders and community elders are the most trusted and accepted individuals by their respective community members. Engaging these individuals in the COVID-19 prevention programs can bridge the gap as people are more inclined to cultural and religious practices. This is consistent with related practice about the Ebola in West Africa and the vital roles of community engagement in preventing the virus. In relation to this, Osoro (2017) indicated that one of the valuable lessons learnt from the Ebola outbreak in Sierra Leone was engaging the communities in response to the outbreak. Community engagement in pandemic prevention ensures trust and confidence in the prevention efforts. It contributes to reporting suspected COVID-19 cases and minimizing stigma and discrimination to those affected. It is vital as cultural insiders and leaders can help address people's misperceptions and enhance trust to encourage health system use (Abramowitz et al., 2015; Kennedy and Nisbett, 2015).

\section{Poverty and the Livelihood Concern}

Poverty and livelihood concerns are the significant challenges in the COVID-19 prevention campaigns in developing countries. This is because the COVID-19 continues to impact people's livelihoods and income opportunities, leading to food insecurity (World Food Program, 2020). Most people in Mekelle are low-income earners that participate in the informal sector, often relying on daily wage to feed their family and cover related expenses. The COVID-19 has posed additional challenges to their livelihoods efforts as most of them are struggling to earn income. Consequently, they are confronting the harsh reality of contracting the virus while working for survival. Observation results have shown that daily laborers in the construction sector, informal businesses, and street vendors have continued their daily activities despite lockdown measures.

People working in the informal sectors have been most affected by COVID-19 response measures such as stay at home orders, closure of open markets and shutdowns in many sectors (Demeke and Kariuki, 2020). The lockdown measures became a predicament for these individuals as the measures threaten their efforts for survival. The challenge is not only for food items but also to cover expenses for personal protection equipment such as face masks, sanitizers and medication. There were several media reports in Mekelle asserting that donors have been supporting people in need in the form of food and sanitation items. But with high levels of need for assistance, these contributions cannot sufficiently satisfy their needs. Overall, the lockdown measures that proved useful in the pandemic prevention campaigns in most of the developed nations seem impractical in Mekelle. One of the reasons for the inapplicability of lockdown measures is that most people rely on daily income to survive and not refrain from attending their workplaces or informal businesses. This, in turn, places individuals at risk and immensely affects the pandemic prevention campaigns.

\section{CONCLUSION}

To contain the rapidly spreading virus, the Tigray State government has adopted different measures endorsed by the World Health Organization. Broadcast media houses have extensively covered the pandemic-related news and programs to educate the public. These programs have positively contributed to raising the awareness of the public about the pandemic. However, there are limited results in realizing behavioral changes among the public in applying the recommended COVID-19 prevention measures. Notably, a limited practice in wearing face masks, a lack of avoiding crowds and no physical distancing in market places, religious institutions, coffee houses, and restaurants. Different factors are affecting the implementation of the recommended prevention measures in Mekelle. These include an increasing level of myths and misconceptions about the pandemic, religious factors associating the COVID-19 with a "punishment from God" or "Allah", a perception that the pandemic affects only the "old", and persistent poverty levels of most people, who ignored the lockdown and stay-at-home measures.

The number of COVID-19 cases has been rapidly increasing in Mekelle. Thus, it obliges introducing the following measures to develop behavior changes among the public. First, it requires understanding the overall context of the intervention setting to identify the nature and preferences, media literacy and related factors of the target population. This helps to design inclusive and relevant messages targeting diversified segments of the public. Second, along with the media messages, it requires promoting interpersonal and group communication to maintain an effective flow of pandemic-related messages among the population. This enhances two-way communication and fosters dialogue at the household and community levels to comply with the preventive measures.

Third, several myths and misconceptions resulting from cultural beliefs and religious practices, seem to distract holistic response toward the pandemic prevention campaigns. Therefore, it necessitates debunking the myths and misconceptions. Lastly, as most people in Mekelle are interconnected through culture and religion, it requires empowering community elders and religious leaders to achieve the desired behavior change among the people. As Gould and Marsh (2004, p.16) argued, "positive health behaviors are more likely to be attained and sustained when the people within a cultural setting are involved in a contextual transformation process." In general, inclusive pandemic prevention communication for a sustained behavior change 
necessitates employing consistent and coordinated messages from different groups, including the media, community elders and religious leaders.

\section{DATA AVAILABILITY STATEMENT}

The raw data supporting the conclusions of this article will be made available by the authors, without undue reservation.

\section{ETHICS STATEMENT}

The studies involving human participants were reviewed and approved by the Ethical review Committee, Mekelle University, College of Health Sciences. The patients/participants provided their written informed consent to participate in this study.

\section{REFERENCES}

Abramowitz, S. A., McLean, K. E., McKune, S. L., Bardosh, K. L., Fallah, M., Monger, J., et al. (2015). Correction: Community-Centered Responses to Ebola in Urban Liberia: The View from below. Plos Negl. Trop. Dis. 9 (4), e0003767. doi:10.1371/journal.pntd.0003767

Airhihenbuwa, C. O., and Obregon, R. (2006). "Excerpt from: A Critical Assessment of Theories/models Used in Health Communication for HIV/ AIDS: Theories and Models of Behavior Change," in Communication for Social Change Anthology: Historical and Contemporary Readings. Editors A. G. Dagron and T. Tufte (South Orange, NJ: Communication for Social Change Consortium), 623-628.

Anderson, R. M., Heesterbeek, H., Klinkenberg, D., and Hollingsworth, T. D. (2020). How Will Country-Based Mitigation Measures Influence the Course of the COVID-19 Epidemic? The Lancet 395 (10228), 931-934. doi:10.1016/ S0140-6736(20)30567-5

Assefa, Y., Damme, W., Williams, O., and Hill, P. (2017). Successes and Challenges of the Millennium Development Goals in Ethiopia: Lessons for the Sustainable Development Goals. BMJ Glob. Health 2 (2), e000318. doi:10.1136/bmjgh2017-000318

Assefa, Y., Gelaw, Y. A., Hill, P. S., Taye, B. W., and Van Damme, W. (2019). Community Health Extension Program of Ethiopia, 2003-2018: Successes and Challenges toward Universal Coverage for Primary Healthcare Services. Glob. Health 15 (1), 24. doi:10.1186/s12992-019-0470-1

Basch, C. H., Mullican, L. A., Boone, K. D., Yin, J., Berdnik, A., Eremeeva, M. E., et al. (2017). Lyme Disease and YouTubeTM: A Cross-Sectional Study of Video Contents. Osong Public Health Res. Perspect. 8 (4), 289-292. doi:10.24171/j. phrp.2017.8.4.10

Bayer, J., Bitiukova, N., Bárd, P., Szakács, J., Alemanno, A., and Uszkiewicz, E. (2019). "Disinformation and Propaganda-Impact on the Functioning of the Rule of Law in the EU and its Member States," Paper No. Law-2019-1341 (Paris Research).

Bekalu, M. A., and Eggermont, S. (2013). Media Use and HIV/AIDS Knowledge: a Knowledge Gap Perspective. Health Promot. Int. 29 (4), 739-750. doi:10.1093/ heapro/dat030

Bracha, H. S. (2004). Freeze, Flight, Fight, Fright, Faint: Adaptationist Perspectives on the Acute Stress Response Spectrum. CNS Spectr. 9 (9), 679-685. doi:10. 1017/s1092852900001954

British Broadcasting Corporation Reality Check. (2020). Coronavirus: What Misinformation Has Spread in Africa? Accessed from https://www.bbc.com/ news/world-africa-51710617.

Carr, E. C. J., and Worth, A. (2001). The Use of the Telephone Interview for Research. NT Res. 6 (1), 511-524. doi:10.1177/136140960100600107

Central Statistics Agency (2016). The 2015/16 Ethiopian Household Consumption-Expenditure Survey. Addis Ababa: Central Statistical Agency.

\section{AUTHOR CONTRIBUTIONS}

This paper is conceptualized and solely written by $\mathrm{HN}$.

\section{ACKNOWLEDGMENTS}

I am grateful to Dr. Rukhsana Ahmed. Also, thankful to the three reviewers for their constructive and insightful comments that contributed to improving the quality of the manuscript.

\section{SUPPLEMENTARY MATERIAL}

The Supplementary Material for this article can be found online at: https://www.frontiersin.org/articles/10.3389/fcomm.2021.562512/ full\#supplementary-material

Central Statistics Agency (2016). The 2016 Demographic And Health Survey. Addis Ababa: Central Statistical Agency.

Chakravorti, B. (2020). As Coronavirus Spreads, So Do Fake News. Bloomberg Opinion. Accessed from www.bloomberg.com/opinion/articles/2020-02-05/ascoronavirus-spreads-sodoes-fake-news.

Cho, H., and Witte, K. (2005). Managing Fear in Public Health Campaigns: A Theory-Based Formative Evaluation Process. Health Promot. Pract. 6 (4), 482-490. doi:10.1177/1524839904263912

Collins, A., Florin, M.-V., and Renn, O. (2020). COVID-19 Risk Governance: Drivers, Responses and Lessons to Be Learned. J. Risk Res. 23, 1073-1082. doi:10.1080/13669877.2020.1760332

Collinson, S., Khan, K., and Heffernan, J. M. (2015). The Effects of Media Reports on Disease Spread and Important Public Health Measurements. PLoS ONE 10 (11), e0141423. doi:10.1371/journal.pone.0141423

Cresswell, J. (2012). Qualitative Inquiry and Research Design: Choosing Among Five Approaches. 3rd ed. London: Sage.

Dahab, M., Van Zandvoort, K., Flasche, S., Warsame, A., Spiegel, P. B., Waldman, R. J., et al. (2020). COVID-19 Control in Low-Income Settings and Displaced Populations: what Can Realistically Be Done? Confl Health 14, 54. doi:10.1186/ s13031-020-00296-8

Dejene, M., and Cochrane, L. (2019). Ethiopia's Developmental State: A Building Stability Framework Assessment. Dev. Pol. Rev 37 (S2), O161-O178. doi:10. 1111/dpr.12414

Del Valle, S., Hethcote, H., Hyman, J. M., and Castillo-Chavez, C. (2005). Effects of Behavioral Changes in a Smallpox Attack Model. Math. Biosciences 195 (2), 228e251. doi:10.1016/j.mbs.2005.03.006

Demeke, M., and Kariuki, J. (2020). Assessing the Impact of COVID-19 on Food and Nutrition Security and Adequacy of Responses in Kenya. FAO.

Dunn, A. G., Leask, J., Zhou, X., Mandl, K. D., and Coiera, E. (2015). Associations between Exposure to and Expression of Negative Opinions about Human Papillomavirus Vaccines on Social Media: an Observational Study. J. Med. Internet Res. 17 (6), e144. doi:10.2196/jmir.4343

Economic Commission for Africa (2020). COVID-19 in Africa: Protecting Lives and Economies. Addis Ababa: Economic Commission for Africa.

Emerson, R. M., Fretz, R. I., and Shaw, L. L. (2011). Writing Ethnographic Field Notes. Chicago: The University of Chicago Press. doi:10.7208/chicago/ 9780226206868.001.0001

Ethiopian Public Health Institute (2005). Determinants of Behavioral Change in HIV/AIDS and IEC-BCC Approaches for Rural Ethiopia. Addis Ababa: Ethiopian Public Health Association.

Ethiopian Public Health Institute. (2020). Notification Note on COVID-19 Situational Update. Accessed from https://covid19.ephi.gov.et/status-updateon-covid19-ethiopia-september-2-2020/

Farmer, J., Bourke, L., Taylor, J., Marley, J. V., Reid, J., Bracksley, S., et al. (2012). Culture and Rural Health. Aust. J. Rural Health 20, 243-247. doi:10.1111/j. 1440-1584.2012.01304.x 
Farr, A. C., Witte, K., Jarato, K., and Menard, T. (2005). The Effectiveness of Media Use in Health Education: Evaluation of an HIV/AIDS Radio Campaign in Ethiopia. J. Health Commun. 10 (3), 225-235. doi:10.1080/10810730590934244

Fernández-Luque, L., and Bau, T. (2015). Health and Social Media: Perfect Storm of Information. Healthc. Inform. Res. 21 (2), 67-73. doi:10.4258/hir.2015.21.2.67

Florida, R. (2020). The Geography of Coronavirus. Accessed from https:// www.citylab.com/equity/2020/04/coronavirus-spread-map-city-urbandensity-suburbs-rural-data/609394/.

Freeman, B., Potente, S., Rock, V., and McIver, J. (2015). Social Media Campaigns that Make a Difference: what Can Public Health Learn from the Corporate Sector and Other Social Change Marketers?. Public Health Res. Pract. 25 (2), e2521517. doi:10.17061/phrp2521517

Frenkel, S., Alba, D., and Zhong, R. (2020). Surge of Virus Misinformation Stumps Facebook and Twitter. The New York Times. https://www.nytimes.com/2020/ 03/08/technology/coronavirus-misinformation-social-media.html.

Frieden, T. R., and Lee, C. T. (2020). Identifying and Interrupting Superspreading Events-Implications for Control of Severe Acute Respiratory Syndrome Coronavirus 2. Emerg. Infect. Dis. 26, 1059-1066. doi:10.3201/eid2606.200495

Funk, S., Gilad, E., Watkins, C., and Jansen, V. A. A. (2009). The Spread of Awareness and its Impact on Epidemic Outbreaks. Proc. Natl. Acad. Sci. 106 (16), 6872-6877. doi:10.1073/pnas.0810762106

Getachew, D. (2005). "Survey of Cultural Appropriateness of HIV/AIDS Communication: The Case of the Gumuz Ethnic Group," Unpublished Master's Thesis (Addis Ababa: Addis Ababa University).

Gobo, G. (2008). Doing Ethnography. London: Sage. doi:10.4135/9780857028976

Gould, H., and Marsh, M. (2004). Culture: Hidden Development. London: Creative Exchange.

Gulilat, M. (2006). "A Study on Trends and Communicative Potentials of 'Dagu' for HIV/AIDS Communication in Afar Region," Unpublished Master's Thesis (Addis Ababa: Addis Ababa University).

Hiwot, D. (2007). "Family Planning Communication in Rural Ethiopia: The Case of Basona Woreda," Unpublished Master's Thesis (Addis Ababa: Addis Ababa University).

Hofstede, G. (2001). Culture's Consequences: Comparing Values, Behaviors, Institutions, and Organisations across Nations. 2nd ed. London: Sage.

Holt, A. (2010). Using the Telephone for Narrative Interviewing: a Research Note. Qual. Res. 10 (1), 113-121. doi:10.1177/1468794109348686

Jack, C. (2017). Lexicon of Lies: Terms for Problematic Information. Data Soc., Accessed from https://datasociety.net/output/lexicon-of-lies/.

Jung, M., Lin, L., and Viswanath, K. (2013). Associations between Health Communication Behaviors, Neighborhood Social Capital, Vaccine Knowledge, and Parents' H1N1 Vaccination of Their Children. Vaccine 31 (42), 4860-4866. doi:10.1016/j.vaccine.2013.07.068

Kennedy, S. B., and Nisbett, R. A. (2015). The Ebola Epidemic: a Transformative Moment for Global Health. Bull. World Health Organ. 93 (1), 2. doi:10.2471/ BLT.14.151068

Kreps, G. L., and Maibach, E. W. (2008). Transdisciplinary Science: The Nexus between Communication and Public Health. J. Commun. 58 (4), 732-748. doi:10.1111/j.1460-2466.2008.00411.x

Kvale, S., and Brinkmann, S. (2008). InterViews: Learning the Craft of Qualitative Research Interviewing. 2nd ed. Thousand Oaks, CA: Sage.

Larson, H. J., Wilson, R., Hanley, S., Parys, A., and Paterson, P. (2014). Tracking the Global Spread of Vaccine Sentiments: The Global Response to Japan's Suspension of its HPV Vaccine Recommendation. Hum. Vaccin. Immunother. 10 (9), 2543-2550. doi:10.4161/21645515.2014.969618

Larson, H. J. (2018). The Biggest Pandemic Risk? Viral Misinformation. Nature 562 (7727), 309. doi:10.1038/d41586-018-07034-4

Majumder, M. S., Kluberg, S., Santillana, M., Mekaru, S., and Brownstein, J. S. (2015). 2014 Ebola Outbreak: Media Events Track Changes in Observed Reproductive Number. Plos Curr. 7. doi:10.1371/currents.outbreaks. e6659013c1d7f11bdab6a20705d1e865

Marshall, C., and Rossman, B. G. (2014). Designing Qualitative Research. London: Sage.

McBain-Rigg, K. E., and Veitch, C. (2011). Cultural Barriers to Health Care for Aboriginal and Torres Strait Islanders in Mount Isa. Aust. J. Rural Health 19, 70-74. doi:10.1111/j.1440-1584.2011.01186.x

Mercy Corps (2020). The Facts: How We're Fighting Hunger in Ethiopia. Accessed from https://www.mercycorps.org/blog/fighting-hunger-ethiopia.
MERQ Consultancy PLC (2019). National Assessment of the Ethiopian Health Extension Program. Addis Ababa: MERQ and Federal Ministry of Health.

Meyer, C. B. (2001). A Case in Case Study Methodology. Field Methods 13 (4), 329-352. doi:10.1177/1525822x0101300402

Michie, S., Fixsen, D., Grimshaw, J. M., and Eccles, M. P. (2009). Specifying and Reporting Complex Behaviour Change Interventions: the Need for a Scientific Method. Implementation Sci. 4, 40. doi:10.1186/1748-5908-4-40

Mo Ibrahim Foundation (2020). COVID-19 in Africa: A Call for Coordinated Governance, Improved Health Structures and Better Data. Accessed from https://mo.ibrahim.foundation/sites/default/files/2020-04/2020-COVID-19in-Africa.

Moemeka, A. (2000). Development Communication in Action: Building Understanding and Creating Participation. Oxford: University Press of America, Inc.

Moorhead, S. A., Hazlett, D. E., Harrison, L., Carroll, J. K., Irwin, A., and Hoving, C. (2013). A New Dimension of Health Care: Systematic Review of the Uses, Benefits, and Limitations of Social Media for Health Communication. J. Med. Internet Res. 15 (4), e85. doi:10.2196/jmir.1933

Nigussie, H. (2019). "Rethinking Indigenous Communication for HIV/AIDS Prevention Campaigns in Ethiopia: the Case of Tigray Region," in Ethiopia: Social, Economic and Political Issues. Editor L. Cochrane (New York: Nova Science Publishers), 145-173.

Obar, J. A., Zube, P., Lampe, C., and Lampe, P. Z. (2012). Advocacy 2.0: An Analysis of How Advocacy Groups in the United States Perceive and Use Social Media as Tools for Facilitating Civic Engagement and Collective Action. J. Inf. Pol. 2, 1-25.

Osoro, E. (2017). Ebola Virus Response: Experiences and Lessons from Sierra Leone. The Conversation. Accessed from https://theconversation.com/ebolavirus-response-experiences-and-lessons-from-sierra-leone-75931.

Oyeyemi, S. O., Gabarron, E., and Wynn, R. (2014). Ebola, Twitter, and Misinformation: a Dangerous Combination? BMJ 349, g6178. doi:10.1136/ bmj.g6178

Padayachee, N., and du Toit, L. C. (2020). Debunking 9 Popular Myths Doing the Rounds in Africa about the Coronavirus. The Conversation. Accessed from https://theconversation.com/debunking-9-popular-myths-doingthe-rounds-in-africa-about-the-coronavirus- 135580.

Panos (2003). Missing the Message? 20 Years of Learning from HIV/AIDS. London: Panos.

Population Stat. (2020). The Population of Mekelle 2020. Accessed from https:// populationstat.com/ethiopia/mekele.

Prati, G., and Pietrantoni, L. (2016). Knowledge, Risk Perceptions, and Xenophobic Attitudes: Evidence from Italy during the Ebola Outbreak. Risk Anal. 36 (10), 2000-2010. doi:10.1111/risa.12537

Pulido, C. M., Villarejo-Carballido, B., Redondo-Sama, G., and Gómez, A. (2020). COVID-19 Infodemic: More Retweets for Science-Based Information on Coronavirus Than for False Information. Int. Sociol. 35, 377-392. doi:10. $1177 / 0268580920914755$

Renn, O. (2015). “Are We Afraid of the Wrong Things? Statistics, Psychology and the Risk Paradox," in The Measurement Of Risk. Union Investment (Frankfurt am Main: Union Investment International), 24-35.

Reynolds, B., H., Galdo, J., and Sokler, L. (2002). Crisis and Emergency Risk Communication. Atlanta: Centers for Disease Control and Prevention.

Rowley, J. (2012). Conducting Research Interviews. Manag. Res. Rev. 35 (3/4), 260-271. doi:10.1108/01409171211210154

Rubin, G. J., Potts, H. W. W., and Michie, S. (2010). The Impact of Communications about Swine Flu (Influenza A H1N1v) on Public Responses to the Outbreak: Results from 36 National Telephone Surveys in the UK. Health Tech. Assess. 14 (34), 183-266. doi:10.3310/hta14340-03

Russonello, G. (2020). Afraid of Coronavirus? that Might Say Something about Your Politics. The New York Times. Accessed from https://www.nytimes.com/ 2020/03/13/us/politics/coronavirus-trump-polling.html.

Scheufele, D. A., and Krause, N. M. (2019). Science audiences, misinformation, and fake news. PNAS 116 (16), 7662-7669.

Scott, J. T., and Maryman, J. (2016). Using Social Media as a Tool to Complement Advocacy Efforts. Glob. J. Community Psychol. Pract. 7, 1-22. doi:10.7728/ 0701201603

Sharma, M., Yadav, K., Yadav, N., and Ferdinand, K. C. (2017). Zika Virus Pandemic-Analysis of Facebook as a Social Media Health Information Platform. Am. J. Infect. Control. 45 (3), 301-302. doi:10.1016/j.ajic.2016.08.022 
Signorini, A., Segre, A. M., and Polgreen, P. M. (2011). The Use of Twitter to Track Levels of Disease Activity and Public Concern in the U.S. During the Influenza A H1N1 Pandemic. PLoS ONE 6 (5), e19467. doi:10.1371/journal.pone.0019467

Singhal, A., and Rogers, E. M. (2003). Combating AIDS: Communication Strategies in Action. New Delhi: Sage.

Singhal, A. (2003). Focusing on the Forest, Not Just the Tree: Cultural Strategies for Combating AIDS. MICA Commun. Rev. 1 (1), 21-28.

Sokolov, M. (2020). The Pandemic Infodemic: How Social Media Helps (And Hurts) during the Coronavirus Outbreak. The Drum. Accessed from https:// www.thedrum.com/opinion/2020/03/03/the-pandemic-infodemic-how-socialmedia-helps-and-hurts-during-the-coronavirus.

Stake, R. E. (2008). "Qualitative Case Studies," in Strategies of Qualitative Inquiry. Editors N. K. Denzin and Y. S. Lincoln. 3rd ed. (Thousand Oaks, CA: Sage), 443-466.

Startt, J. D., and Sloan, W. D. (2003). HISTORICAL METHODS IN MASS COMMUNICATION. USA: Vision Press.

Swanborn, P. (2010). Case Study Research: what, Why, and How? Thousand Oaks, CA: Sage. doi:10.4135/9781526485168

Sypek, S., Clugston, G., and Phillips, C. (2008). Critical Health Infrastructure for Refugee Resettlement in Rural Australia: Case Study of Four Rural Towns. Aust. J. Rural Health 16, 349-354. doi:10.1111/j.1440-1584.2008.01015.x

Taylor, J. (2020). Bat Soup, Dodgy Cures and 'diseasology': The Spread of Coronavirus Misinformation. The Guardian, Accessed from www. theguardian.com/world/2020/jan/31/bat-soupdodgy-cures-and-diseasologythe-spread-of-coronavirus-bunkum.

Tibebe, M. (2006). "Decoding Messages: A Reception Analysis of How Youth Make Sense of HIV/AIDS Messages of 'Yebekal' Radio Program," Unpublished Master's thesis (Addis Ababa: Addis Ababa University).

Tigray Regional Health Bureau Report (2020). COVID-19 Pandemic Preparedness and Response. Weekly Bulletin (September 28, 2020 to October 4, 2020). Accessed from https://www.ephi.gov.et/images/novel_coronavirus/EPHI_ PHEOC_COVID19_Weekly_Bulletin_23_English_100520

Times of Israel. (2020). Madagascar President Claims Herbal Tea Remedy for Coronavirus. Accessed from https://www.timesofisrael.com/madagascarpresident-claims-country-develops-herbal-tea-remedy-for-coronavirus/

Tomeny, T. S., Vargo, C. J., and El-Toukhy, S. (2017). Geographic and Demographic Correlates of Autism-Related Anti-vaccine Beliefs on Twitter, 2009-15. Soc. Sci. Med. 191, 168-175.

Tucker, B. P., and Parker, L. D. (2014). Comparing Interview Interaction Modes in Management Accounting Research: A Case to Answer? AAA 2015 Manag. Account. Section (Mas) Meet. Available at SSRN: https://ssrn.com/abstract=2480247.

Bavel, J. J. V., Baicker, K., Boggio, P. S., Capraro, V., Cichocka, A., Cikara, M., et al. (2020). Using Social and Behavioural Science to Support COVID-19 Pandemic Response. Nat. Hum. Behav. 4, 460-471. doi:10.1038/s41562-020-0884-z

Vogl, S. (2013). Telephone versus Face-To-Face Interviews. Sociological Methodol. 43 (1), 133-177. doi:10.1177/0081175012465967

Wahl-Jorgensen, K. (2020). Coronavirus: How Media Coverage of Epidemics Often Stokes Fear and Panic. The Conversation. Accessed from: https:// theconversation.com/coronavirus-how-media-coverage-of-epidemics-oftenstokes-fear-and-panic-131844

Wakefield, M. A., Loken, B., and Hornik, R. C. (2010). Use of Mass Media Campaigns to Change Health Behaviour. The Lancet 376 (9748), 1261-1271. doi:10.1016/S0140-6736(10)60809-4

Wakefield, M. A., Spittal, M. J., Yong, H.-H., Durkin, S. J., and Borland, R. (2011). Effects of Mass Media Campaign Exposure Intensity and Durability on Quit Attempts in a Population-Based Cohort Study. Health Edu. Res. 26 (6), 988-997. doi:10.1093/her/cyr054

Wang, J., Tang, K., Feng, K., and Lv, W. (2020). High Temperature and High Humidity Reduce the Transmission of COVID-19. Accessed from: https://ssrn. com/abstract $=3551767$.

World Food Program (2020). Impact Of COVID-19 on Livelihoods, Food Security \& Nutrition In East Africa. Urban Focus. UN-Habitat: World Food Program.
World Health Organization (2005). Effective Media Communication during Public Health Emergencies: A WHO Handbook. Geneva: World Health Organisation.

World Health Organization (2011). Report Of the WHO Informal Working Group on Cystic and Alveolar Echinococcosis Surveillance, Prevention and Control, with the Participation of the Food and Agriculture Organization of the United Nations and the World Organization for Animal Health. Geneva: World Health Organization.

World Health Organization (2012). Communication For Behavioral Impact (COMBI): A Toolkit for Behavioral and Social Communication in Outbreak Response. (No. WHO/HSE/GCR/2012.13). World Health Organization.

World Health Organization (2018). Risk Communication and Community Engagement (RCCE) Considerations: Ebola Response in the Democratic Republic of the Congo. Geneva: World Health Organisation.

World Health Organization (2020). "Novel Coronavirus(2019-nCoV)," Situation Report 13, 2 February. Accessed from www.who.int/docs/default-source/ coronaviruse/situation-reports/20200202-sitrep-13-ncov-v3.pdf.

World Health Organization. (2020a). The 2019-nCoV Outbreak Is an Emergency of International Concern. Accessed from http://www.euro.who.int/en/ healthtopics/emergencies/pages/news/news/2020/01/2019-ncov-outbreak-isan-emergency-of-international-concern.

World Health Organization. (2020b). Infodemic Management: Infodemiology. Accessed from https://www.who.int/teams/risk-communication/infodemicmanagement.

World Health Organization. (2020c). Risk Communication and Community Engagement Readiness and Response to Coronavirus Disease (COVID-19): Interim Guidance, 19 March 2020. Accessed from https:/apps.who.int/iris/ handle/10665/331513.

World Health Organization. (2020d). Coronavirus Disease (COVID-19) Advice for the Public: Myth Busters. Accessed from https://www.who.int/emergencies/ diseases/novel-coronavirus-2019/advice-for-public/myth-busters.

Worldometers (2021). The Ethiopian Population in 2021. Accessed from https:// www.worldometers.info/world-population/ethiopia-population/

Xiang, H., Song, N. N., and Huo, H. F. (2016). Modelling Effects of Public Health Educational Campaigns on Drinking Dynamics. J. Biol. Dyn. 10 (1), 164e178. doi:10.1080/17513758.2015.1115562

Yamanis, T., Nolan, E., and Shepler, S. (2016). Fears and Misperceptions of the Ebola Response System during the 2014-2015 Outbreak in Sierra Leone. Plos Negl. Trop. Dis. 10 (10), e0005077. doi:10.1371/journal. pntd.0005077

Yasinski, E. (2020). Can Social Media Inform Public Health Efforts? The Scientist. Accessed from https://www.the-scientist.com/news-opinion/can-social-mediainform-public-health-efforts-66891.

Yin, R. K. (2012). Applications of Case Study Research. 3rd ed. Thousand Oaks, CA: Sage.

Zelalem, T. (2010). "Media Communication Campaign in Promoting Free Public Discussion, Dialogue and Debate on HIV/AIDS and Sexuality-Related Issues: The Case of Amhara Radio," Unpublished Master's thesis (Addis Ababa: Addis Ababa University).

Conflict of Interest: The author declares that the research was conducted in the absence of any commercial or financial relationships that could be construed as a potential conflict of interest.

Copyright $\odot 2021$ Nigussie. This is an open-access article distributed under the terms of the Creative Commons Attribution License (CC BY). The use, distribution or reproduction in other forums is permitted, provided the original author $(s)$ and the copyright owner(s) are credited and that the original publication in this journal is cited, in accordance with accepted academic practice. No use, distribution or reproduction is permitted which does not comply with these terms. 